\title{
EDITORIAL
}

\section{ALCOHOL USE IN THE CZECH REPUBLIC: JOINT STATEMENT OF THE SOCIETY FOR ADDICTION MEDICINE OF THE J. E. PURKYNĚ CZECH MEDICAL ASSOCIATION AND THE CZECH SOCIETY OF CARDIOLOGY}

\author{
Michal Miovský1, Miloš Táborský2, Petr Popov ${ }^{1}$, Aleš Linhart', Tomáš Zima ${ }^{3}$ \\ ${ }^{1}$ Czech Society for Addiction Medicine, Czech Medical Association J. E. Purkyně, Prague, Czech Republic \\ ${ }^{2}$ Czech Society of Cardiology, Brno, Czech Republic \\ ${ }^{3}$ Institute of Medical Biochemistry and Laboratory Diagnostic, First Faculty of Medicine, Charles University and General University Hospital \\ in Prague, Prague, Czech Republic
}

Recent research provides conclusive evidence that it is both professionally and ethically inappropriate to recommend "preventive alcohol use". Alcohol causes more deaths than it can prevent. To recommend moderate drinking with reference to its effectiveness in preventing a specific diagnosis (such as the debated cardioprotective effect) means at the same time to ignore the fact that the risk of another condition (such as liver cirrhosis, stroke, or cancer) may rise significantly. There is a recurrent campaign, in which the media plays a significant role, that continues to establish the notion of the protective health effect of what is referred to as "moderate long-term drinking". While such messages may seem to suggest a major shift or even a breakthrough in the way of looking at the effects of alcohol on people's health, they involve information which has been distorted to some degree or communicated without the relevant context being provided. Such information seeks to give the impression of novelty and a significant development in the perception of alcohol use and its impact (1). Various campaigns, whether past or ongoing, are of service to the alcohol industry on the one hand and to consumers, to defend their drinking behaviour, on the other. The populism and tabloidisation surrounding the topic represent a serious issue which may have negative long-term implications in both clinical and public health terms (2).

A thorough understanding of the impact of alcohol use on people's health requires the explanation of the general context, as isolated evidence and anecdotal findings reported by various studies often allow deliberate or inadvertent misinterpretation of the results (3). It is essential to provide a context, i.e. to present the findings in broader circumstances. The effects of moderate (low-risk, temperate) drinking have developed into a pressing social issue to the extent that public authorities, the agencies responsible for customer protection and food quality, and public health institutions in general have begun to voice their standpoints on it. Recent decades have thus experienced the development of norms/guidelines defining moderate (temperate) drinking (4, 5 ). In the course of time, such guidelines have come into existence in almost all major countries and some of them have been revised repeatedly. There is another good reason why the issue attracts so much attention: economics. In principle, the point is that people can legally buy a substance which evidently and significantly damages their health, or, as the case may be, they cause harm (such as injuries and road accidents) to themselves as a result of using it. And this is where, in addition to social and health insurers, commercial insurance companies step in (by reducing compensation for injuries or accidents involving alcohol, for example). There may also be legal implications (a manufacturer can be sued), which may be viewed as a parallel to the collective, and eventually often successful, lawsuits against the tobacco industry which go back to the 1990s. Since 2016 the Czech Republic has also had its own national document of this kind which was developed by Prof. Jiří Ruprich's team at the Czech National Institute of Public Health (6).

There are different approaches to the classification of alcoholrelated risks. The most consistent view seems to be the one presented by the World Health Organisation (WHO) (7). Another authoritative institution operating under the National Institutes of Health (NIH, USA) is the National Institute on Alcohol Abuse and Alcoholism (NIAAA), which defines moderate/low-risk drinking for women as having no more than three standard drinks (40 $\mathrm{g}$ of ethanol) on any single day and no more than seven drinks per week. For men, the threshold is defined as no more than four standard drinks ( $60 \mathrm{~g}$ of ethanol) on any single day and no more than 14 drinks per week*. While referred to in scores of substance use-related papers, these thresholds were defined in relation to alcohol use disorders. They should not be confused with the thresholds determined for moderate, low-risk drinking in general in relation to other conditions. Indeed, thresholds concerning the risk of negative health consequences in general have been set much lower in the national guidelines. An example of elaborate and comprehensive material, the US guidelines (8) define this threshold as a maximum of 14-28 $\mathrm{g}$ of ethanol per day and $196 \mathrm{~g}$ of ethanol per week for men. For women, the daily intake of ethanol should not exceed $14 \mathrm{~g}$ and $98 \mathrm{~g}$ per day and week, respectively. Very similar definitions of low-risk drinking levels have been

*https://www.niaaa.nih.gov/alcohol-health/overview-alcohol-consumption/moderate-binge-drinking 
adopted by a country neighbouring the Czech Republic, Austria, with $24 \mathrm{~g}$ of ethanol as the maximum daily intake for men and 16 $\mathrm{g}$ for women (9). As for the weekly maximum, Austria set $168 \mathrm{~g}$ of ethanol for men and $112 \mathrm{~g}$ for women. Among our neighbours, Poland has its limits set the highest: $40 \mathrm{~g}$ per day and $280 \mathrm{~g}$ per week for men and $20 \mathrm{~g}$ per day and $140 \mathrm{~g}$ per week for women. For the purposes of the Czech national guidelines, the team of the National Institute of Public Health set the moderate drinking threshold at no more than $24 \mathrm{~g}$ per day for men and $16 \mathrm{~g}$ per day for women. It has also been provided, however, that in order to comply with the definition, a person should refrain completely from alcohol use on at least two days within a week and no more than $40 \mathrm{~g}$ of ethanol should be consumed during a single drinking episode (6).

It is apparent that the development and adoption of a definition of moderate or low-risk drinking is a topical issue not only in medical and public health terms, but also economics-wise (9). Technically speaking, the definition of moderate drinking is determined by the combination of both measures, i.e. the daily and weekly consumption levels of ethanol in grams. The last two decades have seen a growing discussion concerning the effects of alcohol, including those of moderate or low-risk drinking, on human health. Drinking, even low-risk drinking, never involves no risk. It is becoming increasingly evident that even low-risk drinking is associated with a certain degree of risk of adverse health consequences. It holds, at the same time, that the risk threshold is rather fragile and is difficult to generalise.

Comprehensive assessment across diagnoses, i.e. comprehensive assessment of the evidence supporting either the positive or negative effects of alcohol and a comparison of the risks, appears to be a convincing contribution to the discussion on possible health benefits. This approach seems to be much more productive than endless arguments and the itemisation of a single diagnostic group, as is often the case. While extremely time-consuming by nature, this approach appears to make head- way in interpreting the perspective on alcohol use and results in appropriate cautiousness.

A dramatic shift in opinions about the latest standards has been observed as regards cardiovascular conditions. It is hardly possible to advocate alcohol use, regardless of the amount consumed, in the light of the current evidence. No large-scale prospective randomised trial studying the effects of alcohol in terms of both morbidity and mortality has been conducted and, therefore, all the interpretations of the results of the previous studies have no rationale (10). In 2017 and 2018, respectively, two studies were published which significantly enhanced the state of the art in the field. Xi et al. analysed a cohort of 333,247 patients, with a median follow-up of 8.2 years and self-reported alcohol consumption (11). It was found that all-cause mortality - the primary outcome - was lower among individuals who had consumed one, or a maximum of two, alcoholic beverages per week, but it rose significantly with higher levels of consumption.

Another seminal work involved a meta-analysis of 83 prospective studies of alcohol consumption, with the aggregate sample comprising 599,912 individuals (12). Again, the all-cause mortality risk was found to be lower only for individuals with very low levels of alcohol intake - approximately $50 \mathrm{~g}$ per week (Fig. 1).

From a cardiologist's perspective, it can be concluded that the recommended daily dose of alcohol that minimises the risk of loss of health or death is 0 . Although the definition of the maximum tolerable amount based on recent evidence refers to 1-2 drinks per week, there are no ethical and medical grounds for physicians to recommend that their patients use alcohol even to that extent.

The agenda of the health effects of moderate drinking is still subject to further research and debate and, therefore, further specifications and developments can be expected. It is, however, very unlikely that these new findings will bring about any groundbreaking changes in the position on the health effects of moderate drinking. The evidence shows that, for some diseases

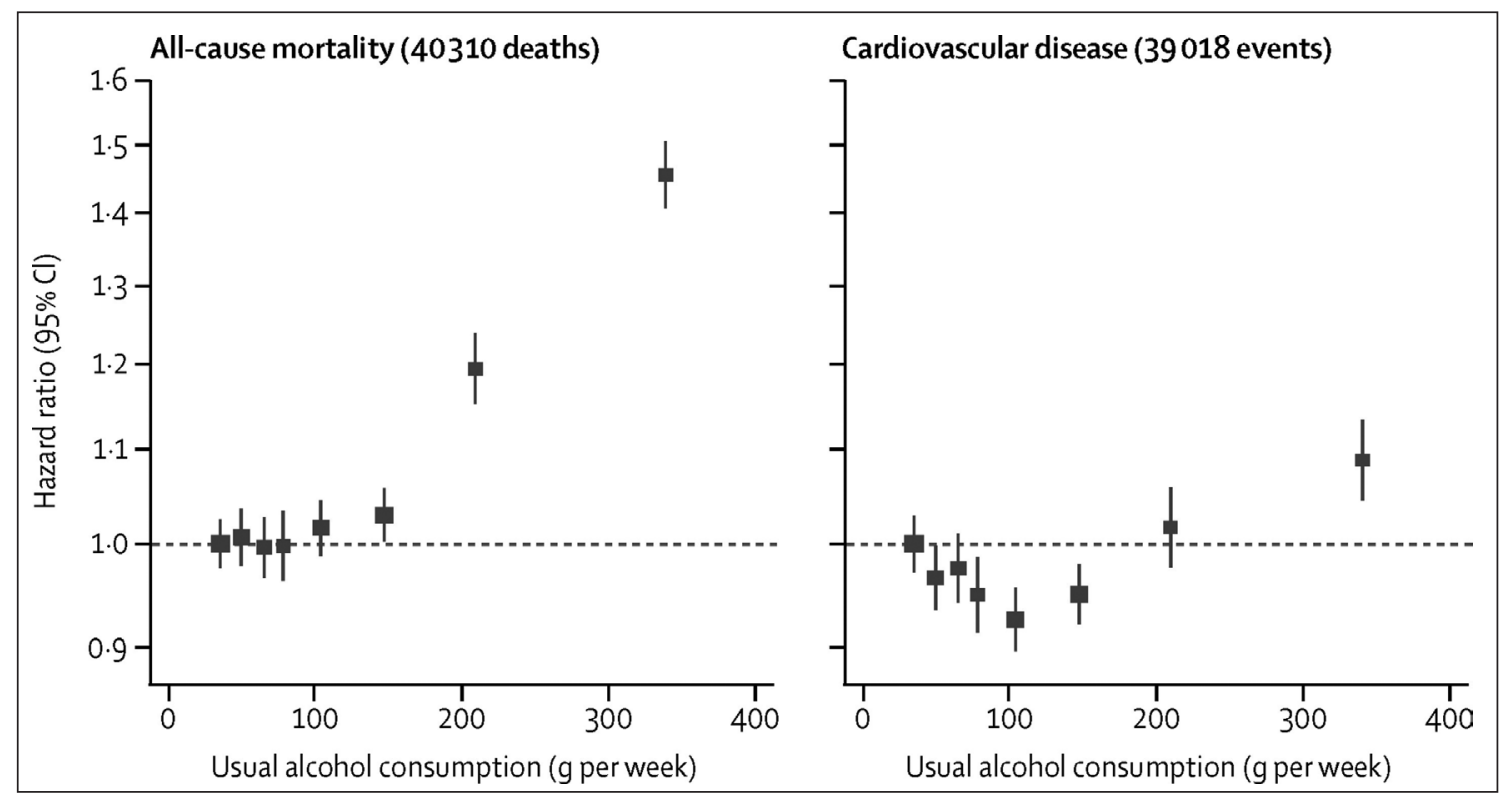

Fig. 1. Relationship between all-cause mortality, cardiovascular disease and weekly alcohol consumption. Source: Wood AM et al. (12). 
and disorders, even alcohol use equivalent to the upper limits of moderate drinking is associated with a more than negligible increase in the relative risk. By no means do the national guidelines recommend any intake of alcohol; they only set the consumption threshold, above which the risks rise significantly. In addition, the guidelines make it explicit, usually throughout the text, that not even "moderate" or "low-risk" drinking means no-risk alcohol use (6) and that the best way to avoid potential (albeit low, in this case) risks is to refrain from consuming alcohol. By no means, however, do the guidelines encourage or advocate alcohol consumption even at the level corresponding to what is referred to as moderate/low-risk drinking. By accepting such an approach to the argumentation and discussion on the part of high-profile professionals, we would subscribe to the distortion of research findings and study results presented to the general public. Moreover, we would participate in the misinterpretation of key documents such as the national guidelines. If we argue in support of "recommended consumption" instead of warning (by pointing out the maximum daily/weekly intake) against the risks and explaining the wider context in which to understand and interpret the national guidelines, as professionals, we move beyond the boundaries of ethical and professionally acceptable discussion intended for the general public, irrespective of the underlying motives for such conduct (13-15).

Recent evidence shows that it is both medically and ethically inappropriate to recommend "preventive" alcohol use. It has been proved that alcohol causes more deaths than it can prevent. To recommend moderate drinking with reference to its preventive effect for a specific diagnosis (such as the cardioprotective effect mentioned here) means at the same time to ignore that the risk of another condition (such as liver cirrhosis or cancer) may rise significantly. The Czech national guidelines set the moderate drinking threshold at no more than $24 \mathrm{~g}$ per day for men and $16 \mathrm{~g}$ per day for women. It has also been provided, however, that in order to comply with the definition, a person should refrain completely from alcohol use on at least two days within a week and no more than $40 \mathrm{~g}$ of ethanol should be consumed during a single drinking episode. Finally, it is also essential to take action aimed at the continuous education of the public and significant restrictions on alcohol advertising.

\section{REFERENCES}

1. Miovský M. Positive effects of moderate alcohol use on human health: the futile search for a third side of the coin. Adiktologie. 2017;17(2):147-60. (In Czech.)

2. Babor T, Hall W, Humphreys K, Miller P, Petry N, West R. Who is responsible for the public's health? The role of the alcohol industry in the WHO global strategy to reduce the harmful use of alcohol. Adiktologie. 2014;14(1):4-6. (In Czech.)

3. Babor T, Caetano R, Casswell S, Edwards G, Giesbrecht N, Graham K, et al. Alcohol: no ordinary commodity: research and public policy. Oxford: Oxford University Press; 2003.

4. Butt P, Gliksman L, Beirness D, Paradis C, Stockwell T. Alcohol and health in Canada: a summary of evidence and guidelines for low-risk drinking. Ottawa: Canadian Centre on Substance Abuse; 2011.

5. Canadian Centre on Substance Abuse. Canada's Low-Risk Alcohol Drinking Guidelines [Internet]. Ottawa: Canadian Centre on Substance Abuse; 2013 [cited 2019 Sep 23]. Available from: https://www.camh.ca/-/media/ files/canadas-low-risk-guidelines-pdf.pdf

6. Suchánková M, Ruprich J, Dofková M, Rehůřková I, Bischofová S, Blahová J. Moderate alcohol consumption: a summary of the national guidelines. Prague: NIPH; 2015. (In Czech.)

7. World Health Organization. Global status report on alcohol and health 2014. Geneva: WHO; 2014.

8. U. S. Department of Health and Human Services; U. S. Department of Agriculture. Dietary Guidelines for Americans: 2015-2020 [Internet]. 2015 [cited 2019 Sep 23]. Available from: https://health.gov/dietaryguidelines/2015/resources/2015-2020_Dietary_Guidelines.pdf

9. Organisation for Economic Co-operation and Development. Tackling harmful alcohol use: economics and public health policy. OECD Publishing; 2015.

10. Šamánek M, Urbanová Z. Wine in prevention of cardiovascular diseases and aging. Interní Med. 2011;13(11):455-6. (In Czech.)

11. Xi B, Veeranki SP, Zhao M, Ma C, Yan Y, Mi J. Relationship of alcohol consumption to all-cause, cardiovascular, and cancer-related mortality in U. S. adults. J Am Coll Cardiol. 2017;70(8):913-22.

12. Wood AM, Kaptoge S, Butterworth AS, Willeit P, Warnakula S, Bolton $\mathrm{T}$, et al. Risk thresholds for alcohol consumption: combined analysis of individual-participant data for 599912 current drinkers in 83 prospective studies. Lancet. 2018;391(10129):1513-23.

13. Chikritzhs T, Stockwell T, Naimi T, Andreasson S, Dangardt F, Liang W. Has the leaning tower of presumed health benefits from 'moderate' alcohol use finally collapsed? Addiction. 2015 May;110(5):726-7.

14. Naimi TS, Babor T, Chikritzhs T, Stockwell TR, McCambridge J, Miller P, et al. Let's not "relax" evidence standards when recommending risky preventive therapeutic agents. Alcohol Clin Exp Res. 2015 Jul;39(7):1275-6.

15. Stockwell T, Zhao J, Panwar S, Roemer A, Naimi T, Chikritzhs T. Do "moderate" drinkers have reduced mortality risk? A systematic review and meta-analysis of alcohol consumption and all-cause mortality. J Stud Alcohol Drugs. 2016 Mar;77(2):185-98.

On behalf of its more than 120 member medical societies, the Board of the J. E. Purkyně Czech Medical Association fully supports the Joint Statement of the Society for Addiction Medicine of the J. E. Purkyně Czech Medical Association and the Czech Society of Cardiology on Alcohol Use in the Czech Republic addressing the issue of excessive alcohol consumption and health professionals' recommendations to patients and the general public. The Board will continue to foster and engage in activities aimed at dispelling the myths about the health benefits of alcohol.

Professor Štěpán Svačina, MD, DrSc,

Chair, J. E. Purkyně Czech Medical Association 